\title{
Color change of lithium disilicate ceramic veneer on different thicknesses with and without glazing
}

\author{
Se-Hoon Kahm ${ }^{1}$, Un-Chang $\mathrm{Heo}^{2}$, and Sung-Joon Kim ${ }^{1 *}$ \\ ${ }^{1}$ Department of Dentistry, School of Medicine, Jeju National University, Jeju 63241, Republic of Korea \\ ${ }^{2}$ School of Medicine, Jeju National University, Jeju 63241, Republic of Korea
}

(Received Feb 13, 2017; Revised version received Mar 15, 2017; Accepted Mar 15, 2017)

\begin{abstract}
The purpose of this study was to compare the translucency and color change of laminate ceramic veneers on different thicknesses before and after glazing. Square-shaped specimens that were $0.3 \mathrm{~mm}, 0.6 \mathrm{~mm}$ and $0.9 \mathrm{~mm}$ thick, respectively, were fabricated with the Styleveneers $(n=30)$. The color coordinates (CIE L* $\left.a^{*} b^{*}\right)$ of the specimens were measured before and after glazing with a colorimeter. For a comparison between the 'not glazed' and 'glazed' groups and among the thicknesses, data were analyzed with a paired T-test, oneway ANOVA test and multiple regression analysis using SPSS $18.0(\mathrm{p}=0.05)$. The translucency parameter $(\mathrm{TP})$ of the $0.3 \mathrm{~mm}$ - and $0.6 \mathrm{~mm}$-thick specimens showed statistically significant differences before and after the glazing process. The one-way ANOVA of color difference $\left(\Delta \mathrm{E}^{*}\right)$ and change of color coordinate $\left(\Delta \mathrm{L}^{*}, \Delta \mathrm{a}^{*}, \Delta \mathrm{b}^{*}\right)$ were statistically different among samples of different thicknesses. The result of the multiple regression analysis showed that $\Delta \mathrm{b}^{*}, \Delta \mathrm{L}^{*}$ improve $\Delta \mathrm{E}^{*}$. Within the limitations of this study, we conclude that the glazing step changes the translucency of $0.3 \mathrm{~mm}$ - and $0.6 \mathrm{~mm}$-thick specimens and the color of lithium disilicate laminate ceramic veneers.
\end{abstract}

KEY WORDS: Color, Laminate, Lithium disilicate, Thickness, Veneer

\section{서 론}

심미 수복에 대한 환자의 관심과 요구가 지속적으로 높 아지고 있으며, 이에 따라 치료 과정에서 최종 수복물에 대한 예측과 잔존 치질, 인접 치은 조직과 자연스러운 형 태와 색조 등이 다각도로 고려되어야 한다. 이러한 상황에 서 자연치와 유사한 투과도를 갖는 도재 보철물의 제작에 대한 요구가 커지고 있다. 각각의 치아는 그 형태, 두께, 굴곡, 표면 상태에 따라서 그 특성이 다르며, 상아질이 법 랑질을 통해 비치는 양상이 달라서 각각 다른 색조를 갖 는다.

특히, 자연치아는 고유의 투명도가 있어 도재 수복물이 그 자연적인 색조와 투명도를 회복하는 것이 필수적이다. 하지만, 투명도가 낮은 상아질과 투명도가 높은 법랑질을 동시에 갖고 있는 자연치의 심미적 특성을 단일 세라믹 수

*Corresponding author: Sung-Joon Kim

Department of Dentistry, School of Medicine, Jeju National University, 15, Aran 13-gil, Jeju-si, Jeju-do 63241, Republic of Korea

Tel.: +82-64-717-1843, Fax: +82-64-727-3114

E-mail: samuelsj@jejunu.ac.kr, samuelsj@empal.com
복재료로 재현하는 것은 쉽지 않다. 자연치아 재현을 위한 심미적 수복물의 제작을 위해서는 치아의 형태와 기능에 필요한 심미적인 색채 과학과 인접 조직과의 조화에 대한 지식이 필요하고[1], 각각의 특성을 갖는 재료를 적층하거 나, 목적에 따른 특별한 수복 재료를 선택하는 과정이 필 수적이다[2].

전치부의 형태, 색조의 개선과 함께 치질의 보존을 위한 수복 방법으로 색조 안정성과 뛰어난 광학적 특성을 가진 세라믹 라미네이트 비니어(Ceramic Laminate Veneer)가 선호된다. 이러한 수복 재료의 색조는 소성 온도, 소성 횟 수, 표면 광택, 세라믹의 두께, 제조사, 하부 구조의 종류 등 다양한 요소에 따라 영향을 받는다[3]. 또한, 사용되는 합착제 종류, 하부 배경 색조, 측정 조명과 재료의 질감에 따라 색조가 달라진다[4]. 도재나 세라믹 제작의 최종 단 계이며, 뛰어난 표면 평활도를 얻기 위한 글레이징 (glazing) 과정을 통해 보철물은 뛰어난 색조 안정성을 얻 게 된다[5]. 이 과정은 보철물을 글레이징 온도에서 1-2분 정도 가열하거나, 약간의 투명한 glass agent를 표면에 적 용, 소성하여 이뤄진다[6]. 글레이징은 높은 온도에서 낮은 팽창성의 표면층 형성이 원리이고, 도재의 표면 강도를 증 가시키는 결과를 얻는데, 자가 글레이징이 표준화된 방법 
이다[7]. 그러나, 라미네이트 비니어는 자가 글레이징을 할 경우 접착면이 글레이징 되는 것이 불필요하므로 바깥면에 만 glazing agent를 적용하여 시행한다. 두 방법 모두 글레 이징 이후 색 변화가 관찰되고, 이는 고온에서 백류석 (Leucite)이나 Lithium disilicate를 포함한 세라믹의 원치 않은 변화에서 유래된 것일 수도 있고, 고온의 소성에 의 하여 세라믹 표면에 화쇄류(pyroclastic stream)가 침착되는 양상으로 설명한다[8].

다른 보철물과 비교할 때 라미네이트의 수복 부위는 얇 고 교합 등의 조정을 필요로 하는 경우가 다른 보철물에 비해 적으므로, 글레이징 이후 상태가 최종 수복물의 색조 가 되는 것이 대부분이다. 기존의 관련 연구로는 수복 대 상 치아의 어두운 배경 색조가 비치는 것을 차단하여 자 연스럽게 재현하기 위한 광학적 특성에 관한 연구들이 있 었고[9-13], 완전 소결된 지르코니아 세라믹(fully sintered zirconia ceramic)에서 글레이징 시행 후 인지할 만한 색차 가 나타났다는 보고는 있었으나[14], 라미네이트의 글레이 징 전후의 광학적 특성의 변화에 관한 연구는 충분하지 않 다. 글레이징 과정을 거치면 Lithium disilicate 성분의 세 라믹 비니어의 투명도는 변하였으나 동일 성분의 제품별 차이는 없었다는 연구가 있었다[15]. 또한 단일 두께의 시 편 실험에서 글레이징 전후의 색 변화가 발생하고, $\operatorname{CIE}$ (Commission Internationale de l'E'clairage, 국제 조명 위원회) $\mathrm{L}^{*} \mathrm{a}^{*} \mathrm{~b}^{*}$ 변수 중 yellow-blue 계열의 $\mathrm{b}^{*}$ 와 lightness 인 $\mathrm{L}^{*}$ 가 영향을 끼친다고 보고하였다[16]. 이에 본 연구의 목적은 Lithium disilicate 성분의 세라믹 라미네이트 비니 어의 글레이징에 따른 여러 두께에서의 투명도와 색조 변 화 양상 등의 광학적인 특성을 알아보기 위한 것이다.

\section{재료 및 방법}

\section{Specimen Preparation}

시편 제작을 위해 Lithium disilicate 성분의 라미네이트 비니어 수복이 가능한 Styleveneers ${ }^{\circledR}(\mathrm{STV}$, The Mint, Seoul, Korea)를 실험에 사용하였다. Styleveneers에는 별도 의 glazing paste가 없는 관계로 glazing paste로 IPS e.max Ceram Glaze를 도포하여 글레이징 하였다(Table 1). 제조 사의 안내된 제작 방법에 따라 시편을 lost wax와 heat pressing technique으로 제작하였다. A1 shade에 해당하는 총 3 가지 $(0.3 \mathrm{~mm}, 0.6 \mathrm{~mm}, 0.9 \mathrm{~mm})$ 두께의 한 변이 $10 \mathrm{~mm}$ 인
정사각형의 시편을 mold를 제작하여 각각 10 개씩 제작했 다(총 30 개). 각 시편은 제작 후 글레이징을 하지 않은 상 태로 첫 번째 색 측정을 하고, 한쪽 면에만 glazing paste 를 도포하여 furnace(Vita Vacumat 40, Vita Zahnfabrik, Bad Säckingen, Germany)에서 $800^{\circ} \mathrm{C}$ 에서 1분간 계류, 글 레이징을 시행한 후 두 번째 색을 측정하였다.

\section{Color Measurement}

시편의 색 측정을 위하여 분광 측색기인 ShadeEye $\mathrm{NCC}^{\circledR}$ Dental Chroma Meter(Shofu inc., Kyoto, Japan)를 사용하 였다. ShadeEye-NCC의 분석모드(Analyze Mode)로 각각 의 시편을 설정된 배경판에서 3 회 측정하여 평균 $\mathrm{CIE}$ $\mathrm{L}^{*} \mathrm{a}^{*} \mathrm{~b}^{*}$ 수치를 얻었다. 색 측정을 위해 숙련된 1 인의 측정 자가 Calibrating tip의 영점 조정을 한 후, 시편 중앙부에 균일하게 접촉, 측정하였다. 시편과 배경판 사이에 optical contact을 높이기 위해 접촉 매개물로 British Standard Institution에 준하여 증류수(refractive index of 1.33)를 이용 하여 밀착하였다[17]. 각 시편은 백색 타일 배경판 $\left(L^{*}=94.78\right.$, $a^{*}=-0.78, b^{*}=-2.40$ ) 위에서 측정하였으며, Translucency Parameter(TP)의 측정을 위해서는 백색과 흑색 배경판이 필요하므로 앞의 측정에서 사용한 백색 타일 배경판 $\left(\mathrm{L}^{*}=94.78, \mathrm{a}^{*}=-0.78, \mathrm{~b}^{*}=-2.40\right)$ 과 흑색 타일 배경판 $\left(\mathrm{L}^{*}=7.58\right.$, $\left.a^{*}=0.15, b^{*}=-3.15\right)$ 을 사용하였다. 1976년 국제 조명 위원 회에서 제정, 가장 일반적으로 사용하는 표색계인 $\mathrm{CIE}$ $\mathrm{L}^{*} \mathrm{a}^{*} \mathrm{~b}^{*}$ system의 3 차원 색공간 좌표인 $\mathrm{L}^{*}$ 값은 Lightness로 100 은 완전한 백색을, 0 은 완전한 검은색을 나타내며 $\mathrm{a}^{*}$ 값 은 Red(+)-Green(-), $b^{*}$ 값은 Yellow(+)-Blue(-)의 요소를 가진 특정 색공간을 의미한다. 글레이징 전후 색차를 나타 내는 $\Delta \mathrm{E}^{*}$ 는 다음 식으로 계산되었다.

$$
\Delta \mathrm{E}^{*}=\left[\left(\Delta \mathrm{L}^{*}\right)^{2}+\left(\Delta \mathrm{a}^{*}\right)^{2}+\left(\Delta \mathrm{b}^{*}\right)^{2}\right]^{1 / 2}
$$

각각의 두께의 $\mathrm{TP}$ 는 다음 식으로 계산되었다.

$$
\mathrm{TP}=\left[\left(\mathrm{L}_{\mathrm{W}}{ }^{*}-\mathrm{L}_{\mathrm{B}}{ }^{*}\right)^{2}+\left(\mathrm{a}_{\mathrm{W}}{ }^{*}-\mathrm{a}_{\mathrm{B}}{ }^{*}\right)^{2}+\left(\mathrm{b}_{\mathrm{W}}{ }^{*}-\mathrm{b}_{\mathrm{B}}{ }^{*}\right)^{2}\right]^{1 / 2}
$$

아래 첨자 $\mathrm{W}$ 와 $\mathrm{B}$ 는 각각 백색 타일 배경과 흑색 타일 배경에서 측정했음을 나타내며, 측정된 값은 흑색과 백색 배경에서 동일 시편의 색차를 의미하여 숫자가 클수록 투 명한 재료이고, 불투명 재료의 경우는 TP가 0 이 된다[18].

\section{Statistical Analysis}

통계처리는 0.05 유의수준에서 SPSS Win 18.0 program

Table 1. Experimental material and glazing agent manufactured

\begin{tabular}{lllc}
\hline \multicolumn{1}{c}{ Material } & \multicolumn{1}{c}{ Classification } & \multicolumn{1}{c}{ Manufacturer } & Shade \\
\hline Styleveneers & Pressable lithium disilicate & The Mint LLC (Seoul, Korea) & A1 \\
IPS e.max Ceram Glaze & Glazing paste & Ivoclar Vivadent AG (Schaan, Liechtenstein) & - \\
\hline
\end{tabular}


(SPSS Inc., Chicago, IL, USA)을 이용하였으며, 각각의 두 께의 글레이징 전후 차이는 대응표본 T-test를, 글레이징 전후의 각 군 간의 색 변화 차이는 one-way ANOVA로 분 석 하였고, 영향을 주는 색좌표의 관련성 분석은 $\Delta \mathrm{E}^{*}$ 를 종속변수로 하여 다중 회귀 분석을 시행하였다.

\section{결 과}

$0.3 \mathrm{~mm}, 0.6 \mathrm{~mm}$ 시편에서 글레이징을 시행한 군과 시 행하지 않은 군의 $\mathrm{TP}$ 는 통계적으로 유의하게 높아진 평균 값의 차이를 보였고 $(p<0.05), 0.9 \mathrm{~mm}$ 군에서는 통계적인 유의성이 없었다. $0.3 \mathrm{~mm}, 0.6 \mathrm{~mm}$ 군에서 글레이징을 시 행한 시편의 TP가 높아졌으며, $0.6 \mathrm{~mm}$ 두께의 시편이 $0.3 \mathrm{~mm}$ 시편보다 더 큰 $\mathrm{TP}$ 증가율을 보였다. 평균 $\mathrm{TP}$ 증 가율은 글레이징 전 TP에 비하여 $0.3 \mathrm{~mm}$ 군에서 $8.34 \%$, $0.6 \mathrm{~mm}$ 군에서 $25.84 \%$ 로 나타났으며, $0.9 \mathrm{~mm}$ 군에서는 $1.01 \%$ 이었다(Table 2, Fig. 1).

두께별 글레이징 전후 색차 변화는 Fig. 2에 나타나 있 으며, 색차와 각 색 좌표 변화의 one-way ANOVA 결과는 Table 3 과 같다. $\Delta \mathrm{L} *$ 의 두께별 차이는 $0.3 \mathrm{~mm}$ 시편에서는 증가하여 밝아진 것으로 나타났으나, $0.6 \mathrm{~mm}$ 와 $0.9 \mathrm{~mm}$ 군에서는 어두워져 감소했다. red-green 계열 변화인 $\Delta \mathrm{a}^{*}$ 의 값은 다른 변수에 비해 가장 적었고, $\Delta \mathrm{b}^{*}$ 값은 $0.3 \mathrm{~mm}$ 와 $0.6 \mathrm{~mm}$ 군에서는 감소하여 blue 계열로 변한 것으로 나타났으나 $0.9 \mathrm{~mm}$ 군에서는 증가하여 red 계열로 변하였 다. $\Delta \mathrm{E}^{*}$ 는 $0.3 \mathrm{~mm}$ 군에서는 4.17 로 가장 컸었으며, $0.9 \mathrm{~mm}$ (2.70), $0.6 \mathrm{~mm}(1.45)$ 의 순이었다. 시편 두께별 $\Delta \mathrm{L}^{*}, \Delta \mathrm{a}^{*}$, $\Delta \mathrm{b}^{*}, \Delta \mathrm{E}^{*}$ 모두 의 통계적 유의한 평균값의 차이를 보였다 $(p<0.05)$.

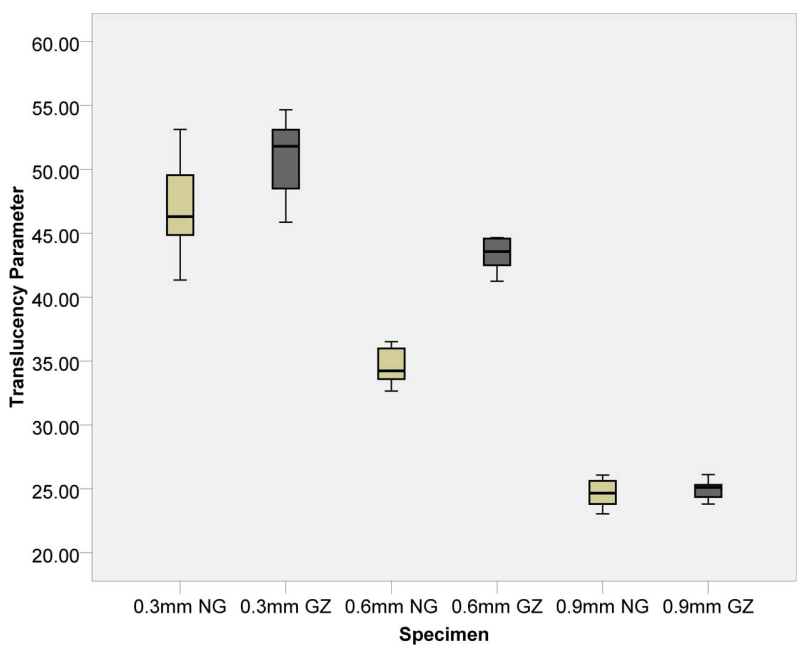

Fig. 1. TP changes of each experimental group; NG: Not Glazed, GZ: Glazed.

$0.3 \mathrm{~mm}, 0.6 \mathrm{mmm} 0.9 \mathrm{~mm}$ 와 전체 시편을 대상으로 $\Delta \mathrm{E}^{*}$ 에 미치는 색 좌표 요인의 관련성을 분석 하기 위한 다중 회귀 분석 결과는 Table 4 와 같다. $0.3 \mathrm{~mm}$ 군에서 색 좌표의 상관관계는 $\mathrm{R}=0.994$ 이었고, 회귀선 설명력 $\mathrm{R}^{2}$ 은 0.987 이었으며, adjusted $\mathrm{R}^{2}$ 은 0.981 로 설명력은 $98.1 \%$ 로 높게 나타났다. 관련 평가 요소 중 $\Delta \mathrm{a}$ *는 통계적으로 유 의하지 않았으며, $\Delta \mathrm{b}^{*}, \Delta \mathrm{L}^{*}$ 이 영향을 미치고 있었다. $\Delta \mathrm{b}^{*}$ 의 영향력은 $-0.239, \Delta \mathrm{L}^{*}$ 의 영향력은 1.086 이었다. 0.6 $\mathrm{mm}$ 군에서 색 좌표의 상관관계는 $\mathrm{R}=0.963$ 이었고, 회귀선 설명력 $\mathrm{R}^{2}$ 은 0.928 이었으며, adjusted $\mathrm{R}^{2}$ 은 0.892 로 설명력 은 $89.2 \%$ 로 나타났다. 관련 평가 요소 중 $\Delta \mathrm{a}^{*}$ 는 통계적으 로 유의하지 않았으며, $\Delta \mathrm{b}^{*}, \Delta \mathrm{L}^{*}$ 이 영향을 미치고 있었다. $\Delta \mathrm{b} *$ 의 영향력은 $-0.540, \Delta \mathrm{L} *$ 의 영향력은 -0.557 이었다. $0.9 \mathrm{~mm}$ 군에서 색 좌표의 상관관계는 $\mathrm{R}=0.998$ 이었고, 회

Table 2. TP values and paired T-test results of specimen between before and after glazing in each thickness

\begin{tabular}{|c|c|c|c|c|c|c|}
\hline \multirow{2}{*}{ Thickness } & \multicolumn{2}{|c|}{ Before glazing } & \multicolumn{2}{|c|}{ After glazing } & \multirow{2}{*}{$p$-value } & \multirow{2}{*}{$\begin{array}{l}\text { Increased } \\
\text { percentage }\end{array}$} \\
\hline & Mean & SD & Mean & SD & & \\
\hline $0.3 \mathrm{~mm}$ & 47.03 & 3.65 & 50.95 & 3.05 & $0.035^{*}$ & 8.34 \\
\hline $0.6 \mathrm{~mm}$ & 34.48 & 1.28 & 43.39 & 1.20 & $0.000^{*}$ & 25.84 \\
\hline $0.9 \mathrm{~mm}$ & 24.70 & 1.06 & 24.95 & 0.70 & 0.602 & 1.01 \\
\hline
\end{tabular}

*Significantly different compared to test groups $(p<0.05)$

Table 3. Changes of color coordinates and one-way ANOVA results of each thickness between before and after glazing

\begin{tabular}{cccccccc}
\hline $\begin{array}{c}\text { Color } \\
\text { coordinate }\end{array}$ & \multicolumn{2}{c}{$0.3 \mathrm{~mm}$} & \multicolumn{2}{c}{$0.6 \mathrm{~mm}$} & \multicolumn{2}{c}{$0.9 \mathrm{~mm}$} & \multicolumn{2}{c}{$p$-value } \\
\hline$\Delta \mathrm{L}^{*}$ & Mean & $\mathrm{SD}$ & Mean & SD & Mean & SD & $0.000^{*}$ \\
$\Delta \mathrm{a}^{*}$ & -0.72 & 1.36 & -0.42 & 0.78 & -1.80 & 0.33 & $0.028^{*}$ \\
$\Delta \mathrm{b}^{*}$ & -1.55 & 0.23 & 0.01 & 0.14 & -0.16 & 0.18 & $0.000^{*}$ \\
$\Delta \mathrm{E}^{*}$ & 4.17 & 1.24 & -1.22 & 0.42 & 1.96 & 0.54 & $0.000^{*}$ \\
\hline
\end{tabular}

*Significantly different compared to test groups $(p<0.05)$ 


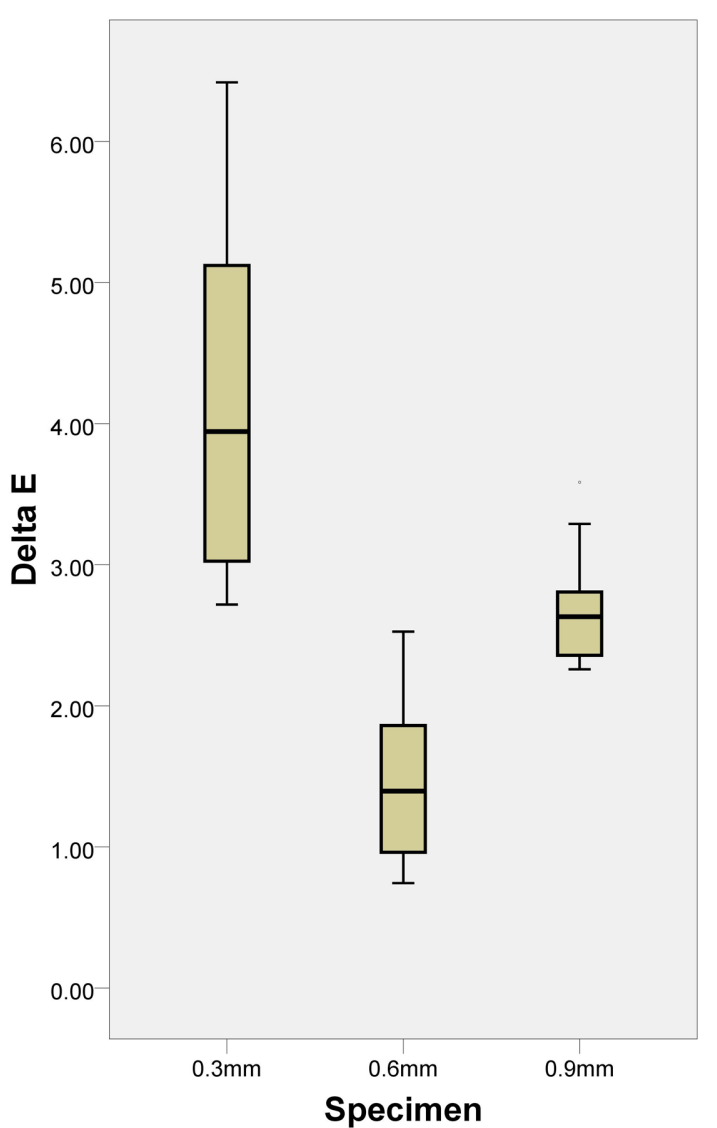

Fig. 2. Color difference of each experimental group before and after glazing.

귀선 설명력 $\mathrm{R}^{2}$ 은 0.995 이었으며, adjusted $\mathrm{R}^{2}$ 은 0.993 로 설명력은 $99.3 \%$ 로 높았다. 관련 평가 요소 중 $\Delta \mathrm{a}^{*}$ 는 통계 적으로 유의하지 않았으며, $\Delta \mathrm{b}^{*}, \Delta \mathrm{L} *$ 이 영향을 미치고 있
었다. $\Delta \mathrm{b}$ *의 영향력은 $0.904, \Delta \mathrm{L} *$ 의 영향력은 -0.581 이었 다. 전체 시편을 대상으로 한 상관관계는 $\mathrm{R}=0.823$ 이었고, 회귀선 설명력 $\mathrm{R}^{2}$ 은 0.678 이었으며, adjusted $\mathrm{R}^{2}$ 은 0.641 로 설명력은 $64.1 \%$ 이었다. 관련 평가 요소는 다른 군과 마찬 가지로 $\Delta \mathrm{a}^{*}$ 는 통계적으로 유의하지 않았으며, $\Delta \mathrm{b}^{*}, \Delta \mathrm{L} *$ 이 영향을 미치고 있었다. $\Delta \mathrm{b} *$ 의 영향력은 $0.467, \Delta \mathrm{L} *$ 의 영 향력은 0.896 이었다.

\section{교 찰}

자연스러운 치아 색조의 재현을 위해 각각의 수복재의 투명도와 광학적 특성을 이해하는 것은 필수적인 사항이 다. 간접 수복에 사용되는 이상적인 심미 재료는 투명도를 비롯하여, 명도, 채도 색상 등의 각 요소에 대한 이해와 함 께 상황에 따른 조절을 할 수 있어야 한다[19]. 강도를 높 인 세라믹 재료는 투명도가 낮아지는 경향이 있으므로 [12], 임상적 요구에 따라 강도와 광학적 특성을 고려한 적 절한 재료의 선택을 하여야 한다. 장석형 도재(feldspathic porcelain)가 가장 높은 투명도를 나타내지만[4,11], 약한 강 도의 보강을 위해 장석형 도재의 glass matrix에 다른 성분 을 추가하면 투명도를 저해하여 심미성이 나빠진다. 이와 비교할 때, Lithium disilicate 세라믹의 가장 큰 장점은 강 도를 감소시키지 않고도 얇게 만들 수 있고, 높은 투명도 의 심미성이 뛰어난 보철물 제작이 가능한 점이다[4]. 또 다른 장점으로 Lithium disilicate는 높은 기계적 강도와 치 질과의 접착의 용이성을 제공하는 장점이 있으며, 상당히 낮은 굴절률 특성이 있어 매우 투명도가 높다[20].

본 연구는 Lithium disilicate 성분의 세라믹 라미네이트

Table 4. Multiple regression analysis for color difference $\left(\Delta \mathrm{E}^{*}\right)$ of each thickness between before and after glazing.

\begin{tabular}{cccccccl}
\hline Thickness & Variables & $\mathrm{B}$ & Std. Error & $\beta$ & $\mathrm{t}$ & $p$-value & Dependent Variable: $\Delta \mathrm{E}^{*}$ \\
\hline \multirow{4}{*}{$0.3 \mathrm{~mm}$} & $\Delta \mathrm{L}^{*}$ & 0.993 & 0.071 & 1.086 & 14.075 & $0.000^{*}$ & $\mathrm{~F}=156.766\left(p=0.000^{*}\right)$ \\
& $\Delta \mathrm{a}^{*}$ & 0.048 & 0.368 & 0.009 & 0.132 & 0.900 & $\begin{array}{l}\mathrm{R}=0.994, \mathrm{R}^{2}=0.987 \\
\text { Adj. } \mathrm{R}^{2}=0.981\end{array}$ \\
& $\Delta \mathrm{b}^{*}$ & -0.326 & 0.088 & -0.239 & -3.712 & $0.010^{*}$ & $\begin{array}{l}\text { Durbin-Watson=2.199 } \\
0.6 \mathrm{~mm}\end{array}$ \\
& $\Delta \mathrm{L}^{*}$ & -0.416 & 0.092 & -0.557 & -4.500 & $0.004^{*}$ & $\mathrm{~F}=25.673\left(p=0.001^{*}\right)$ \\
& $\Delta \mathrm{a}^{*}$ & 0.311 & 0.513 & 0.078 & 0.606 & 0.567 & $\mathrm{R}=0.963, \mathrm{R}^{2}=0.928$ \\
& $\Delta \mathrm{b}^{*}$ & -0.746 & 0.179 & -0.540 & -4.166 & $0.006^{*}$ & $\begin{array}{l}\text { Adj. } \mathrm{R}^{2}=0.892 \\
\text { Durbin-Watson=1.700 }\end{array}$ \\
& $\Delta \mathrm{L}^{*}$ & -0.769 & 0.038 & -0.581 & -20.206 & $0.000^{*}$ & $\mathrm{~F}=414.526\left(p=0.000^{*}\right)$ \\
$0.9 \mathrm{~mm}$ & $\Delta \mathrm{a}^{*}$ & -0.036 & 0.075 & -0.014 & -0.472 & 0.654 & $\begin{array}{l}\mathrm{R}=0.998, \mathrm{R}^{2}=0.995 \\
\text { Adj. } \mathrm{R}^{2}=0.993\end{array}$ \\
& $\Delta \mathrm{b}^{*}$ & 0.734 & 0.025 & 0.904 & 29.506 & $0.000^{*}$ & $\begin{array}{l}\text { Durbin-Watson }=1.801 \\
\text { All thickness }\end{array}$ \\
& $\Delta \mathrm{L}^{*}$ & 0.488 & 0.091 & 0.896 & 5.361 & $0.000^{*}$ & $\mathrm{~F}=18.258\left(p=0.000^{*}\right)$ \\
& $\Delta \mathrm{a}^{*}$ & -1.149 & 0.888 & -0.173 & -1.293 & 0.207 & $\begin{array}{l}\mathrm{R}=0.823, \mathrm{R}^{2}=0.687 \\
\text { Adj. } \mathrm{R}^{2}=0.641\end{array}$ \\
& $\Delta \mathrm{b}^{*}$ & 0.374 & 0.124 & 0.467 & 3.019 & $0.006^{*}$ & Durbin-Watson=1.894 \\
\hline
\end{tabular}

*Significantly different compared to test groups $(p<0.05)$ 
비니어의 글레이징 효과를 각각의 두께에 따른 투명도와 색조 변화를 종속변수로 하여 광학적인 특성을 알아보기 위한 것이다. 시편을 각각 $0.3 \mathrm{~mm}, 0.6 \mathrm{~mm}, 0.9 \mathrm{~mm}$ 두께 로 제작한 것은 통상적인 라미네이트 비니어의 두께가 0.3-0.9 mm 범위라는 보고[21]를 고려한 것이다. $0.3 \mathrm{~mm}$ 와 $0.6 \mathrm{~mm}$ 군에서는 글레이징 시행 후 투명도가 증가하 는 양상을 나타닜으나 $0.9 \mathrm{~mm}$ 군는 투명도 변화가 없는 것 으로 나타났다. 이는 얇은 두께에서는 글레이징 과정이 영 향을 끼칠 수 있으나, 어느 정도 이상의 두께에서는 효과 가 없는 것으로 추론할 수 있다. $0.3 \mathrm{~mm}$ 군보다 $0.6 \mathrm{~mm}$ 군에서 투명도가 더 증가한 이유로 이미 투명도가 높은 상 태의 $0.3 \mathrm{~mm}$ 군의 천정효과가 나타난 것으로 추측해볼 수 있으나, 이는 향후 연구가 필요하다. 이 결과에 근거할 때, 보철물의 두께에 따라서 글레이징 이후 투명도가 달라지 는 양상을 고려하여야 하며, 임상적으로 글레이징 전에 색 조를 판단할 경우에는 최종 글레이징 후 투명도가 증가하 여 기대했던 색조와 다른 결과가 나타날 수 있음을 고려 해야 한다. Heffernan등은 글레이징을 시행하면 각 core material의 비니어링 세라믹의 불투명도(opacity)가 낮아지 며, 투명도가 높아진다고 보고하였다[10]. Heffernan등의 실험에서 사용한 Contrast Ratio와 본 연구의 $\mathrm{TP}$ 와는 투명 도 측정법은 다르지만, 같은 결과를 보였다. 수복 재료의 적절한 투명도에 대한 기준은 임상 상황에 따라 다를 수 있다. 전치부에서 자연치 색조를 반영하면서 형태의 변화 를 위해서는 투명도가 높은 것이 적합할 것이지만, 수복물 하방의 변색된 치질 또는 불투명한 코어 재료 색조를 차 단할 목적이라면 투명도가 낮은 것이 적합하다.

글레이징 이후 색차와 각 색좌표 변화는 각 두께 군에 서 모두 통계적으로 유의한 차이를 보였으나, 수복물 두께 에 따른 색좌표의 변화 방향과 색차는 각각 다른 양상을 보여주었다. $\Delta \mathrm{L}^{*}$ 은 $0.3 \mathrm{~mm}$ 에서 증가하여 밝아진 양상을 보였으나, $0.6 \mathrm{~mm}$ 군과 $0.9 \mathrm{~mm}$ 군에서는 감소하여 어두워 진 것으로 나타났고, $\Delta \mathrm{a}^{*}$ 은 그 변화폭이 적어 red-green 계 열의 변화가 적었다. $\Delta \mathrm{b}$ *는 $0.3 \mathrm{~mm}$ 군과 $0.6 \mathrm{~mm}$ 군에서는 감소하여 blue 계열로 변화하였으나, $0.9 \mathrm{~mm}$ 군에서는 증 가하여 yellow 계열로 변화되었다. $\Delta \mathrm{a}$ *과 $\Delta \mathrm{b}^{*}$ 값은 각 그 룹에서 일관된 양상이 보이지 않았는데, 이는 다른 연구에 서도 확인되는 양상이었으나[3,22], $\mathrm{L} *$ 의 변화가 각각 다 른 이유는 불명확하다. $\Delta \mathrm{E}^{*}$ 는 $0.3 \mathrm{~mm}$ 군이 가장 컸으며, $0.9 \mathrm{~mm}, 0.6 \mathrm{~mm}$ 군의 순이었다. $\Delta \mathrm{E}^{*}=1$ 의 값은 통제 조건 에서 $50 \%$ 의 관찰자가 색 차이를 인지할 수 있는 수준을 나타낸다[23]. 일반 관찰자나 환자가 인지 할 수 있는 정 도의 $\Delta \mathrm{E}^{*}$ 는 2.72 로 보고되며[24], 임상적으로 허용되는 $\Delta \mathrm{E}^{*}$ 값에 대해서는, $\Delta \mathrm{E}^{*} \leq 3.3[25], \Delta \mathrm{E}^{*} \leq 3.7[26]$ 등 다양한 연구가 있다. 이런 문헌들을 참고로 할 때 $0.3 \mathrm{~mm}$ 군에서 의 색차는 4.17 로 큰 값을 보여 임상적으로 얇은 비니어로
수복시에는 글레이징 전에 시적하는 것은 재고할 필요가 있을 것이다. $\Delta \mathrm{E}^{*}$ 에 영향을 미치는 색 좌표 요인분석을 위해 각 두께 시편 군과 전체 두께 시편군을 대상으로 한 결과 모두 $\Delta \mathrm{L}^{*}, \Delta \mathrm{b}^{*}$ 이 영향을 미치는 것으로 나타났다. 이는 $0.6 \mathrm{~mm}$ 단일 두께의 다른 두 제조사의 시편을 측정 한 연구[16]와 같은 결과로 나타났으나, 각 영향력은 두께 별로 다른 양상을 보였다.

$\mathrm{Chu}$ 등의 연구[11]에 따르면 두께의 변화는 직접적으로 세라믹 수복물의 명도에 영향을 끼치게 된다. 두께가 증가 함에 따라 TP가 낮아지는 경향을 보인다고 하였으나 $[4,8,13]$, 글레이징으로 재료 표면의 평활도가 변화될 경우 에는 명도가 가장 큰 변화를 보인다고 하였고[9], 이는 TP 값의 변화에 영향을 주었다고 연관 지을 수 있다. 또한 이 과정은 표면 평활도를 높이고 내부 공극율을 감소시켜 굽 힘강도(flexural strength)를 증가시킨다고 알려져 있다[19]. $0.3 \mathrm{~mm}$ 보다 $0.6 \mathrm{~mm}$ 두께 시편의 $\mathrm{TP}$ 증가율이 더 컸던 것 에 대한 가능한 설명으로, 시편이 두꺼울수록 더 깊게 글 레이징 효과가 나타났거나, 글레이징 이후 높아지는 $\mathrm{TP}$ 는 두께와는 무관하게 어느 정도의 한계치가 있다는 설명이 있다[15]. 본 실험의 $0.9 \mathrm{~mm}$ 시편에서는 통계적 유의성이 없었던 것으로 보아, 일정 두께 이상의 시편에서는 TP변 화가 미미한 것으로 가정할 수 있다. 이는 코어 재료에 비 니어링을 시행하여 두께가 $1.5 \mathrm{~mm}$ 인 시편에서는 glazing 효과가 시편 투명도의 유의한 차이를 보이지 않았다는 연 구[27]와 일치한다.

글레이징 과정 외에도 라미네이트 세라믹의 임상 과정 과 기공 과정은 여러 단계를 거치며, 단계에 따라서 최종 색조에 영향을 주게 된다. 연구에 따르면, 비니어 표면에 접착을 위한 Sandblasting과 레이져 조사를 시행한 군이 더 불투명한 결과를 보였고, 불산 처리를 한 비니어는 TP가 영향을 받지 않았으며, 비니어의 두께가 얇을 때 더 큰 영 향을 받는다고 하였다[28]. 그러므로 실제 임상 환경에서는 접착의 각 과정 이후 색 변화에 대한 고려가 필요하다.

본 연구는 Lithium disilicate 성분의 A1 shade의 Styleveneers 로 제작한 한정된 연구이며, 제작 시편 두께의 종류도 불 연속적이며 제한적이다. 또한 글레이징 시행 후 투명도와 색조 변화를 정량적으로 예측하는 데에는 한계가 있다. 향 후 다양한 성분의 재료, glazing agent 종류에 따른 영향, 여러 색조, 다양한 두께에서의 $\mathrm{TP}$ 와 색변화의 예측 가능한 모델 등 다양한 임상 상황에 관한 연구가 필요할 것이다.

Lithium disilicate 성분의 라미네이트 비니어 세라믹의 각 두께에 따른 글레이징 전후에 따른 $\mathrm{TP}$ 와 색조 변화를 측정한 결과, $\mathrm{TP}$ 는 $0.3 \mathrm{~mm}$ 와 $0.6 \mathrm{~mm}$ 군에서 통계적으로 유의하게 높아져 투명해진 것으로 나타났다. 색차와 각 색 좌표 변화는 각 두께 군에서 모두 통계적으로 유의한 차 이를 보였으며, $\Delta \mathrm{E}^{*}$ 에 영향을 미치는 색 좌표 요인분석을 
위해 한 결과 $\Delta \mathrm{L}^{*}, \Delta \mathrm{b}^{*}$ 이 영향을 미치는 것으로 나타났다.

\section{감사의 글}

This research was supported by the 2016 scientific promotion program funded by Jeju National University.

\section{Conflict of Interest}

The authors declare that they have no competing interests.

\section{ORCID}

Se-Hoon Kahm 0000-0001-6945-8480

Un-Chang Heo 0000-0001-8489-4635

Sung-Joon Kim 0000-0003-0603-4036

\section{References}

1. Ryu SY, Lim JH, Cho IH. A study on the color stability of porcelain for porcelain fused to metal crown. J Korean Acad Prosthodont 2000;38:73-84.

2. Joiner A. Tooth colour: a review of the literature. J Dent 2004;32:3-12. doi: http://dx.doi.org/10.1016/j.jdent.2003. 10.013 .

3. Al Ben Ali A, Kang K, Finkelman MD, Zandparsa R, Hirayama H. The Effect of Variations in Translucency and Background on Color Differences in CAD/CAM Lithium Disilicate Glass Ceramics. J Prosthodont 2014; 23:213-220. doi: 10.1111/jopr.12080.

4. Barizon KT, Bergeron C, Vargas MA, Qian F, Cobb DS, Gratton DG, Geraldeli S. Ceramic materials for porcelain veneers: part II. Effect of material, shade, and thickness on translucency. J Prosthet Dent 2014;112:864-870. doi: 10.1016/j.prosdent.2014.05.016.

5. Yilmaz C, Korkmaz T, Demirköprülü H, Ergün G, Ozkan Y. Color stability of glazed and polished dental porcelains. J Prosthodont. 2008;17:20-24. doi: 10.1111/j.1532849X.2007.00237.x.

6. Wiskott. Fixed prosthodontics: principles and clinics. London: Quintessence publishing Co. Ltd; 2011. p. 670671.

7. Choi BB. Contemporary Fixed Prosthodontics 3rd Edition. Seoul: Jisung; 2003. p. 645.

8. Yilmaz K, Gonuldas F, Ozturk C. The effect of repeated firings on the color change of dental ceramics using different glazing methods. J Adv Prosthodont 2014;6:427433. doi: 10.4047/jap.2014.6.6.427.

9. Obregon A, Goodkind RJ, Schwabacher WB. Effects of opaque and porcelain surface texture on the color of ceramometal restorations. J Prosthet Dent 1981;46:330-340. doi: 10.1016/0022-3913(81)90222-5.

10. Heffernan MJ, Aquilino SA, Diaz-Arnold AM, Haselton DR, Stanford CM, Vargas MA. Relative translucency of six all-ceramic systems. Part II: core and veneer materials. J Prosthet Dent 2002;88:10-15. doi: 10.1067/mpr. 2002.126795.

11. Chu FC, Chow TW, Chai J. Contrast ratios and masking ability of three types of ceramic veneers. J Prosthet Dent 2007;98:359-364. doi: 10.1016/S0022-3913(07)60120-6.

12. Spear F, Holloway J. Which all-ceramic system is optimal for anterior esthetics? J Am Dent Assoc 2008; 139:S19-S24. doi: 10.14219/jada.archive.2008.0358.

13. Baek KW, Kim SJ. Thickness and translucency of opaque shade composite resin for masking effect. J Korean Dent Assoc 2011;49:203-210.

14. Sinmazisik G, Demirbas B, Tarcin B. Influence of dentin and core porcelain thickness on the color of fully sintered zirconia ceramic restorations. J Prosthet Dent 2014;111:142-49. doi: 10.1016/j.prosdent.2013.09.016.

15. Kahm SH, Kim SJ. Translucency of ceramic veneers on glazing effect. J Korean Acad Prosthodont 2015;53:138143. doi: 10.4047/jkap.2015.53.2.138.

16. Kahm SH, Lee BJ, Seo MS, Kim SJ. Color difference of lithium disilicate ceramic veneer on glazing effect. Oral Biology Research 2016;40:124-128. doi: 10.21851/obr. 40.3.201609.124.

17. British standard specification for dental porcelains for jacket crowns. BS5612. London: British Standard Institution; 1978.

18. Johnston WM, Ma T, Kienle BH. Translucency parameter of colorants for maxillofacial prostheses. Int J Prosthodont 1995;8:79-86.

19. Santos MO, do Amaral FL, França FM, Basting RT. Influence of translucence/opacity and shade in the flexural strength of lithium disilicate ceramics. J Conserv Dent 2015;18:394-398. doi: 10.4103/0972-0707.164053.

20. McLaren EA, Cao PT. Ceramics in dentistry - part I: classes of materials. Inside Dent 2009;5:94-103.

21. Bagis B, Turgut S. Optical properties of current ceramics systems for laminate veneers. J Dent 2013;41:e24-e30. doi: 10.1016/j.jdent.2012.11.013.

22. Lee YK, Yu B, Lim HN. Lightness, chroma, and hue distributions of a shade guide as measured by a spectroradiometer. J Prosthet Dent 2010;104:173-181. doi: 10.1016/ S0022-3913(10)60116-3.

23. Kuehni RG, Marcus RT. An experiment in visual scaling of small color differences. Color Res Appl 1979;4:83-91. 
doi: 10.1111/j.1520-6378.1979.tb00094.x.

24. Ragain JC, Johnston WM. Color acceptance of direct dental restorative materials by human observers. Color Res Appl 2000;25:278-285. doi: 10.1002/1520-6378 (200008)25:4<278::AID-COL8>3.0.CO;2-F.

25. Ruyter IE, Nilner K, Moller B. Color stability of dental composite resin materials for crown and bridge veneers. Dent Mater 1987:3:246-251. doi: 10.1016/S0109-5641 (87)80081-7.

26. Johnston WM, Kao EC. Assessment of appearance match by visual observation and clinical colorimetry. $\mathrm{J}$ Dent Res 1989;68:819-822.

27. Kurtulmus-Yilmaz S, Ulusoy M. Comparison of the translucency of shaded zirconia all-ceramic systems. J Adv Prosthodont 2014;6:415-422. doi: 10.4047/jap.2014. 6.5.415.

28. Turgut S, Bagis B, Ayaz EA, Korkmaz FM, Ulusoy KU, Bagis YH. How will surface treatments affect the translucency of porcelain laminate veneers? J Adv Prosthodont. 2014;6:8-13. doi: 10.4047/jap.2014.6.1.8. 